\title{
Visual censuses around drifting fish aggregating devices (FADs): a new approach for assessing the diversity of fish in open-ocean waters
}

\author{
J. C. Gaertner ${ }^{1, *}$, M. Taquet ${ }^{2}$, L. Dagorn ${ }^{3}$, B. Mérigot $^{1}$, R. Aumeeruddy ${ }^{4}$, G. Sancho ${ }^{5}$, \\ D. $\operatorname{Itano}^{6}$ \\ ${ }^{1}$ Centre d'Océanologie de Marseille, Université de la Méditerranée, LMGEM, UMR CNRS 6117, Rue de la batterie des \\ Lions 13007 Marseille, France \\ ${ }^{2}$ Institut français de recherche pour l'exploitation de la mer (IFREMER), and ${ }^{3}$ Institut de Recherche pour le Dévelopement, \\ CRH, Avenue Jean Monnet BP 171 - 34203 Sète Cedex, France \\ ${ }^{4}$ Seychelles Fishing Authority, Fishing Port, PO Box 449, Victoria, Mahé, Seychelles \\ ${ }^{5}$ College of Charleston, Grice Marine Laboratory, 205 Fort Johnson Road, Charleston, South Carolina 29412, USA \\ ${ }^{6}$ Pelagic Fisheries Research Program, University of Hawaii, 1000 Pope Road, MSB 312, Honolulu, Hawaii 96822, USA
}

\begin{abstract}
This study provides a baseline measure of pelagic fish species diversity around fish aggregating devices (FADs) in the Western Indian Ocean. Using data from visual censuses made by SCUBA divers around drifting FADs we (1) analysed 11 diversity indices describing 4 main components of pelagic diversity: number of species, evenness, taxonomic diversity and rarity and (2) discussed the viability of using visual censuses around FADs to monitor temporal and spatial changes in diversity patterns of pelagic fishes in the future. Our results not only show that a single index, such as species richness or the Shannon-Wiener index, cannot provide a complete description of pelagic fish diversity around FADs, but also that some components of diversity appear to be multifaceted themselves and require the simultaneous use of several complementary indices in order to be accurately described and monitored. Despite a limited sampling effort, our results suggest that using visual censuses around FADs could provide reproducible 'relative' indices of diversity for a welldelimited assemblage of species (intra- and extranatant species in the epipelagic domain). In this context, we propose a preliminary 'short list' of diversity indices based firstly on their complementarity and secondly on their simplicity. While visual censuses of pelagic fishes at FADs (like any other sampling method) cannot give an exhaustive picture of diversity, they are a fishery-independent survey method that can complement other sampling techniques and provide reproducible information to monitor the diversity of these very difficult-to-access pelagic fish communities.
\end{abstract}

KEY WORDS: Pelagic fishes · Diversity · Drifting FADs · Indian Ocean

\section{INTRODUCTION}

Loss of biodiversity has been of increasing concern in recent years. Most of the scientific effort dedicated to studying species diversity has been devoted to the terrestrial domain, but marine studies have been on the increase during the last 2 decades (e.g. Ellingsen 2001, Gray 2002, Gaertner et al. 2007, etc.). The vast majority of these marine studies only concern benthic fauna, however. To date, very little is known about the diversity of open-ocean pelagic fishes (Massuti et al. 1999, Smith \& Brown 2002, Worm et al. 2003) primarily because of the nektonic behaviour of pelagic fish species in these large ecosystems and the great difficulty of regularly accessing pelagic ecosystems to directly collect diversity data. Up to now, most of the biodiversity data on the pelagic fish communities come directly from commercial fisheries. While this data collection system may provide useful and abundant databases, it also suffers from several drawbacks when it is used for 
the purpose of biodiversity studies. For instance, commercial fisheries are usually focused on the capture of some commercially valuable species and they provide poorly standardized data restricted to the main fishing grounds, while very mobile pelagic species occupy wider areas (Fonteneau et al. 2000). The general lack of standardized baselines of fisheries-independent databases that allow derivation of pelagic fish diversity information strongly limits our ability to assess the effects of natural or anthropogenic pressure on the diversity of pelagic ecosystems.

In order to monitor the diversity of pelagic fishes in an ecosystem, one needs appropriate data and analytical tools. We here propose and discuss (1) an innovative way for collecting diversity data on pelagic ecosystems and (2) an analytical framework to define a set of complementary diversity indices to be used for monitoring. First, pelagic fish species occupy extensive areas in the open ocean and are usually too loosely aggregated to observe well. However, fish aggregating devices (FADs) are used by fishermen all over the world in tropical and subtropical areas because they attract and aggregate many pelagic species (Fonteneau et al. 2000, Fréon \& Dagorn 2000, Castro et al. 2001, Dempster \& Taquet 2004). We hypothesized that utilizing fisheries-independent observations around FADs may also help scientists to access and monitor the diversity of pelagic fish species. Second, several authors have recently shown in both terrestrial and benthic marine ecosystems that diversity is a more complex and multifaceted concept than previously expected (Purvis \& Hector, 2000, Wilsey et al. 2005, Mérigot et al. 2007a). Here, we propose the first analysis of the multi-component aspect of species diversity dealing with open-ocean pelagic fishes. For this purpose we investigated the empirical relationships among 11 indices belonging to 4 of the main components of biodiversity (number of species, evenness, taxonomic diversity and rarity). With this premise, we discuss the viability of using visual censuses around FADs to (1) define a 'short list' of indices that best describe the multi-component features of these pelagic fish communities and (2) monitor the diversity patterns of pelagic fishes in the future. Finally, we provide the first baseline measures of pelagic species diversity in the Western Indian Ocean using this approach.

\section{MATERIALS AND METHODS}

Experiments and sampling design. We used data collected within the framework of the European programme FADIO (Fish Aggregating Devices as Instrumented Observatories of pelagic ecosystems). Five offshore cruises were performed around the Seychelles archipelago between 2003 and 2005 at the end of the southeast monsoon season (September 2003 and October 2004 and 2005) and in the middle of the northwest monsoon season (February 2004 and 2005). A total of 22 standardized underwater visual fish censuses made around different drifting FADs were analyzed. The general area of study expanded around the Seychelles archipelago, from $0^{\circ} 01^{\prime} \mathrm{N}$ to $9^{\circ} 06^{\prime} \mathrm{S}$, but 20 of the 22 censuses were located between $2^{\circ} 10^{\prime} \mathrm{S}$ and $6^{\circ} 49^{\prime} \mathrm{S}$, and $49^{\circ} 48^{\prime} \mathrm{E}$ and $57^{\circ} 58^{\prime} \mathrm{E}$ (Fig. 1). We therefore assumed that our samples came from the same oceanic region. We visited existing drifting FADs that had been deployed by commercial tuna purse seiners. From this aspect, this sampling design is comparable to diversity studies using observers' data onboard commercial vessels (e.g. Worm et al. 2003), where the spatial strategy of sampling is dictated by fishermen and not scientists. Moreno et al. (2007) have shown from empirical knowledge of fishermen that non-tuna species (i.e. the species sampled in the present study, see below) seem to begin aggregating to drifting FADs a short time after deployment (within 1 to $3 \mathrm{wk}$ ). Although the exact 'ages' of the 22 FADs of the present study were not known, we know that they were at least 3 to $4 \mathrm{wk}$ old, based on information provided by the fishermen who gave us the locations of the FADs. Of course, an 'old' aggregation could have been fished just before our visual survey by another boat other than those of the owner of the FAD. Most of the time, the aggregation does not re-start from scratch, as a lot of

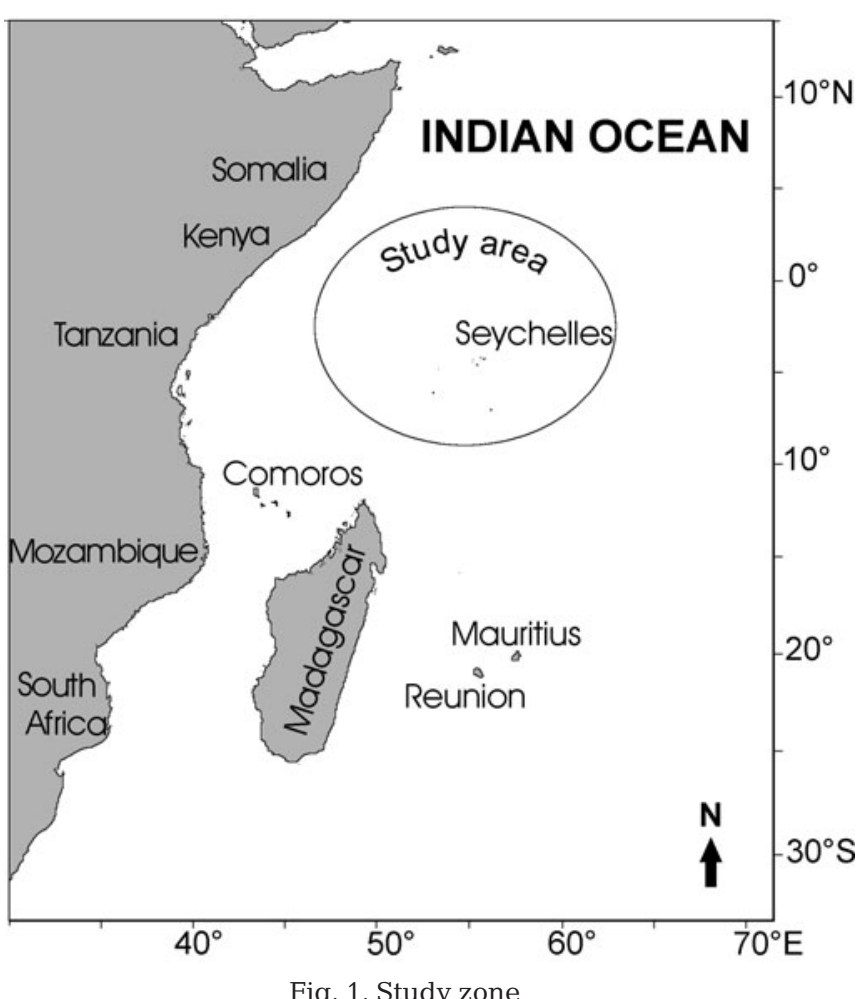

Fig. 1. Study zone 
fishes remain around the FAD (for instance, small species are not captured by the purse seine net). In our case, such a situation was unlikely because when fishing of a FAD belonging to a different ship occurs, the electronic tag that provides geographical position of the FAD is replaced by the 'new owner', making the FAD inaccessible to us. In addition, we only observed limited signs of possible recent fishing (skin scars on a very limited number of fishes) on only 2 out of the 22 FADs visited, and those aggregations were not different from the others. We therefore consider that the FADs surveyed were 'old' FADs comparable in terms of their aggregations.

Dives were performed by divers equipped with SCUBA. One diver, always the same for the whole set of visual censuses, noted all the species encountered along with their abundance estimates. An initial scan of the surface waters was made to identify and count small intranatant species, i.e. those that live in close association (<0.5 m; Parin \& Fedoryako 1999) with the FAD. For these species that inhabit the first $2 \mathrm{~m}$ from the FAD, the minimum size observed was $10 \mathrm{~mm}$ (divers could easily approach those species for accurate identification). Divers would then descend to a depth of $15 \mathrm{~m}$ below the FAD which allowed them to visually survey deeper waters to ca. $30 \mathrm{~m}$. This method is comparable to the stationary point-count technique commonly used in demersal and reef visual censuses (Samoilys \& Carlos 2000). The depths of the divers ( 0 to $15 \mathrm{~m}$ ) and the visibility of the waters defined the semi-spherical volume of water centered on the FADs (horizontal radius of $25 \mathrm{~m}$ and a vertical radius of $30 \mathrm{~m}$ ). The duration of each underwater visual census was standardized at 30 min (Taquet et al. 2007). Direct abundance estimates of individuals by species were conducted when fish schools consisted of less than 50 individuals, while more abundant species were estimated by assigning them to abundance classes. Each underwater visual census was complemented by a recording with an underwater video camera. The diver with the video camera would first record each fish species found in close aggregation with the FAD and then, from a stationary point $15 \mathrm{~m}$ below the FAD, would slowly spin around $360^{\circ}$ and film all the fishes swimming around that position (Taquet et al. 2007). The video camera was equipped with a wide angle lens to better estimate the abundance of schooling species. Videos were immediately viewed after each survey to verify the species lists and refine abundance estimates made underwater by the main diver.

Circumnatant species (i.e. species with an aggregation radius of a few hundred meters from the FAD, like tropical tuna; Parin \& Fedoryako 1999, Fréon \& Dagorn 2000) and species usually found deeper than $50 \mathrm{~m}$ were occasionally observed but not included in the analyses. We considered that our sampling tech- nique was not appropriate to accurately estimate the presence and abundance of such species.

Diversity indices and statistical analyses. We investigated the diversity patterns of pelagic fish assemblages through the simultaneous analysis of 4 major components of diversity (1) species richness, (2) rarity, (3) evenness and (4) species taxonomy.

We first analysed the number of species, which is still the most widely used component of diversity in both marine and terrestrial ecosystems (Rosenzweig 1995, Gaston \& Spicer 1998, Gaertner et al. 2005). Because species richness is highly sensitive to sampling effort (Gaston \& Spicer 1998), we checked that variations in the duration of the 22 visual censuses did not affect values in species richness through a chi-squared test of independence ( $p>0.05)$. Thus, we considered the number of species per visual census as a measure of species density $(S)$ (Table 1$)$. In addition, we computed Margalef's species richness index $\left(D_{\mathrm{mg}}\right)$ (Margalef 1958), which adjusts the number of species according to the total number of individuals sampled in each census. Further, we carried out rarefaction curves to roughly assess the degree of exhaustivity of our sampling effort. Rarefaction curves plot the cumulative number of species recorded as a function of sampling effort, which was taken as the number of individuals observed (for individual-based curves) or the cumulative number of samples (for sampled-based curves). Rarefaction curves were produced by repeatedly and randomly re-sampling (20 times) a pool of $\mathrm{N}_{1}$ visual censuses for the sample-based curve (or a pool of $\mathrm{N}_{2}$ individuals for the individual-based curve) plotting the average number of species represented by $1,2, \ldots, N_{1}$ visual censuses (or $\mathrm{N}_{2}$ individuals).

Second, we considered rarity, which is a component that is extensively used in conservation studies. Rarity is usually defined on the basis of the level of species local abundance or the species range size (occurrence), but whatever the approach used, definitions of rarity are necessarily arbitrary (Gaston 1994). Because species with a restricted range are usually the most vulnerable to environmental change (Thomas \& Mallorie 1985), the species range size criterion has been the most widely used for conservation purposes. Hereafter, rare species are those that occurred in less than $5 \%$ of the 22 visual censuses. Three species were below this threshold and thus considered as rare in the present study (Fig. 2).

Third, we analysed the evenness component of diversity. We considered 2 indices of evenness (Table 1). The Heip's evenness index ( $E_{\text {Heip }}$ ) (Heip 1974) was computed because it is assumed to be mainly sensitive to variation in rare species (Beisel et al. 2003) and is less sensitive to variation in the number of species (Smith \& Wilson 1996) than the most widely used even- 
Table 1. Species diversity components and descriptors studied. $x_{i}(i=1, \ldots, S)$ denotes the abundance of the $i$ th species, $N\left(=\sum_{i} X_{i}\right)$ is the total number of individuals in the sample, $p_{i}\left(=x_{i} N^{-1}\right)$ is the proportion of all individuals belonging to species $i, N_{\text {max }}$ is the number of individuals of the most abundant species, $\omega_{i j}$ is the 'distinctness weight' given to the path length linking species $i$ to the first common node with species $j$ in the hierarchical classification. Double summations are over all pairs of species $i$ and $j$ (note that the distance between 2 individuals of the same species is set to 0 ). Indices based on presence-absence data are marked by ${ }^{a}$

\begin{tabular}{|c|c|c|c|c|}
\hline Component & Descriptor name & Formula & Expected properties & Source \\
\hline \multirow[t]{2}{*}{ Species richness } & Species density $^{a}$ & $\begin{array}{l}S=\text { number of species } \\
\text { by visual census }\end{array}$ & $\begin{array}{l}\text { Standardize species } \\
\text { richness per unit area }\end{array}$ & \\
\hline & Margalef & $D_{\mathrm{mg}}=\frac{S-1}{\ln (N)}$ & Adjusted species richness by $N$ & Margalef (1958) \\
\hline Rarity & Rarity $^{\mathrm{a}}$ & $\begin{array}{l}\text { Rarity }=\text { no. species } \\
\text { with }<5 \% \text { occurrence }\end{array}$ & $\begin{array}{l}\text { Define rarity in terms } \\
\text { of species range size }\end{array}$ & \\
\hline \multirow[t]{2}{*}{ Evenness } & Heip & $E_{\text {Heip }}=\frac{\exp \left(H^{\prime}\right)-1}{S-1}$ & Sensitive to rare species & Heip (1974) \\
\hline & Berger Parker & $\frac{1}{d}=\frac{N}{N_{\max }}$ & $\begin{array}{l}\text { Sensitive to dominant } \\
\text { species }\end{array}$ & $\begin{array}{l}\text { Berger \& Parker } \\
(1970)\end{array}$ \\
\hline \multirow[t]{2}{*}{$\begin{array}{l}\text { No. of species } \\
+ \text { evenness }\end{array}$} & Shannon-Wiener & $H^{\prime}=-\sum_{i=1}^{S} p_{i} \log p_{i}$ & Sensitive to rare species & $\begin{array}{l}\text { Shannon \& Weaver } \\
\text { (1949) }\end{array}$ \\
\hline & Simpson diversity & $1-D=1-\left(\sum_{i}^{S} p_{i}^{2}\right)$ & Sensitive to dominant species & Simpson (1949) \\
\hline \multirow[t]{4}{*}{ Species taxonomy } & Taxonomic diversity & $\Delta=2 \frac{\sum \sum_{i<j} \omega_{i j} X_{i} X_{j}}{N(N-1)}$ & $\begin{array}{l}\text { Extension of } D \text { including } \\
\text { taxonomic relatedness }\end{array}$ & $\begin{array}{l}\text { Warwick \& Clarke } \\
\text { (1995) }\end{array}$ \\
\hline & $\begin{array}{l}\text { Taxonomic } \\
\text { distinctness }\end{array}$ & $\Delta^{*}=\frac{\sum \sum_{i<j} \omega_{i j} X_{i} x_{j}}{\sum \sum_{i<j} x_{i} X_{j}}$ & $\begin{array}{l}\text { Form of } \Delta \text { limiting the } \\
\text { influence of species dom- } \\
\text { inance, reflecting pure } \\
\text { taxonomic relatedness }\end{array}$ & $\begin{array}{l}\text { Warwick \& Clarke } \\
\text { (1995) }\end{array}$ \\
\hline & $\begin{array}{l}\text { Average taxonomic } \\
\text { distinctness }^{\mathrm{a}}\end{array}$ & $\Delta^{+}=2 \frac{\sum \sum_{i<j} \omega_{i j}}{S(S-1)}$ & $\begin{array}{l}\text { Equivalent to } \Delta \text { and } \Delta^{*} \\
\text { in presence-absence data }\end{array}$ & $\begin{array}{l}\text { Clarke \& Warwick } \\
\text { (1998) }\end{array}$ \\
\hline & $\begin{array}{l}\text { Variation in taxo- } \\
\text { nomic distinctness }^{\mathrm{a}}\end{array}$ & $\begin{array}{l}\Lambda^{+}=2 \frac{\sum \sum_{i<j}\left(\omega_{i j}-\bar{\omega}\right)^{2}}{S(S-1)} \\
\text { where } \bar{\omega}=\Delta^{+}\end{array}$ & $\begin{array}{l}\text { Evenness of the taxonomic } \\
\text { level distribution in the } \\
\text { taxonomic tree }\end{array}$ & $\begin{array}{l}\text { Clarke \& Warwick } \\
\text { (2001) }\end{array}$ \\
\hline
\end{tabular}

ness index, the Pielou index $\left(J^{\prime}\right)$, which is also based on the Shannon-Wiener index $\left(H^{\prime}\right)$ (Shannon \& Weaver 1949). Complementary to the Heip index, we computed the Berger Parker index $(d)$ (Berger \& Parker 1970) because it is only sensitive to variations in the most dominant species. Here, we computed $1 / d$ which increases when abundances are evenly distributed (maximum diversity) among the species and decreases with dominance.

We also computed 2 heterogeneous indices, $H^{\prime}$ and the Simpson concentration index (D) (Simpson 1949), which combine both the number of species and evenness components in a single value (Table 1). $H^{\prime}$ is assumed to be sensitive to the changes in abundance of rare species while $D$ is heavily weighted towards the dominant species and is less sensitive to species richness than $H^{\prime}$ (Boyle et al. 1990). We used Simpson diversity $(1-D)$, rather than $D$, which increases in value with diversity. Although they are not focused on a single diversity component, we used these 2 very popular heterogeneous indices to facilitate comparisons of our results with other works.

Fourth, we computed 4 taxonomic indices proposed by Warwick and Clarke (see Table 1) that quantify the taxonomic diversity of a faunal assemblage in terms of average distance of all pairs of individuals (or species) in a sample by tracing these distances through a Linnaean taxonomic tree. Each of these indices has specific properties. The taxonomic diversity $(\Delta)$ is the average distance (path length) traced through the taxonomic tree between every pair of individuals in a sample, including the individuals which belong to the same species, whereas taxonomic distinctness $\left(\Delta^{*}\right)$ considers individuals which only belong to different species (Warwick \& Clarke 1995). In comparison to $\Delta$, $\Delta^{*}$ is expected to be more closely a function of pure 


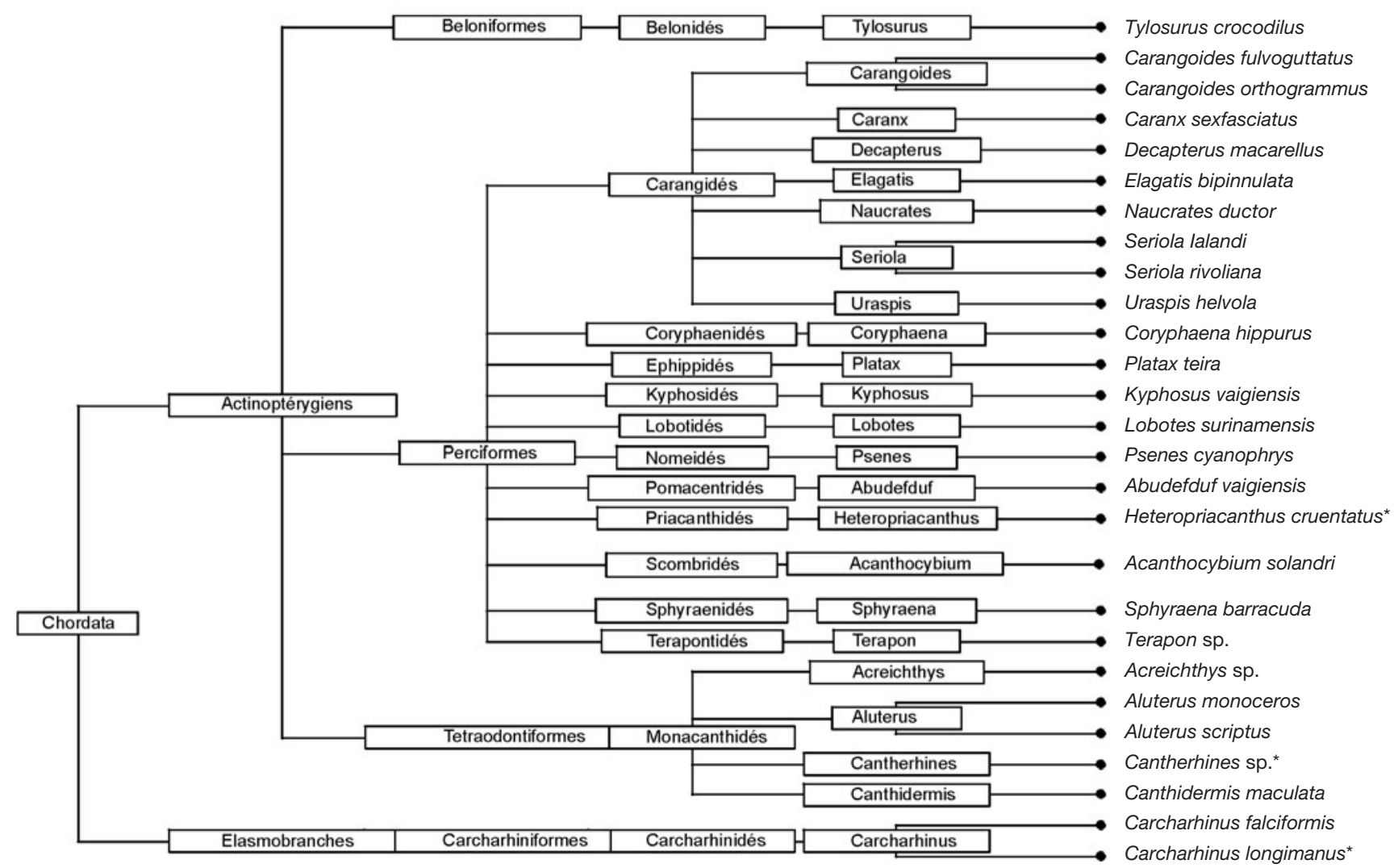

Fig. 2. Taxonomic tree of observed pelagic fishes (see electronic appendix for an illustration at www.int-res.com/articles/suppl/ m366p175_app.pdf. Rare species are asterisked

taxonomic relatedness of individuals (Clarke \& Warwick 1998).

Because sampling presence-absence data can be easier and less time consuming than collecting abundance data, we also investigated a third taxonomic index $\left(\Delta^{+}\right)$in order to study the possible 'loss of information' with respect to the previous taxonomic indices requiring abundance data. $\Delta^{+}$can be considered as the average distance traced through a taxonomic tree between each pair of species in the presence-absence dataset (Clarke \& Warwick 1998). In addition, we applied the index of variation in taxonomic distinctness $\left(\Lambda^{+}\right)$, which is based on the evenness of the taxonomic level distribution in a taxonomic tree and is calculated as the variance of $\Delta^{+}$(Table 1 ). There are 2 main methods to define $\left(\omega_{i j}\right)$, which is the weight given to the path length linking species $i$ and $j$ in the taxonomic tree (Clarke \& Warwick 1999). Rogers et al. (1999) showed that $\Delta^{+}$, calculated with and without $\omega_{i j}$, modified to reflect the quantitative reduction in taxon richness, was strongly correlated. Thus, we adopted the simplest form of $\omega_{i j}$ with equal step-lengths between each successive taxonomic level, setting the $\omega_{i j}$ at 100 for 2 species connected at the highest (taxonomically coarsest) possible level (Clarke \& Warwick 1999).
Two sample $t$-tests for unequal variance distributions (i.e. Welch's test) were carried out to investigate the effects of the sampling season on the variation of each of the selected descriptors of diversity. We also investigated with the same method our assumption that the sampling zone was homogeneous. Due to the relatively small sample size, the distributions of Welch's statistics under null hypothesis were obtained by randomisation ( $n=500)$. The north-south comparison of the study zone was done on either side of latitude $4.5^{\circ} \mathrm{S}$, and the east-west comparison was done on either side of longitude $55^{\circ} 30^{\prime} \mathrm{E}$. The limited number of visual censuses did not allow the analysis of the sampling zone effect at a finer scale.

Finally, a 2-stage procedure was carried out to identify both redundant and complementary descriptors of diversity. In a first stage, we analysed the multicomponent structure of pelagic fish diversity through the use of principal component analyses (PCA). Because atypical values of some descriptors could strongly influence the correlation coefficients based on abundance data, we carried out a PCA based on the Spearman's rank correlation matrix (Jolliffe 1986). This consists in computing a classical PCA on the ranks of diversity indices values. The projection of diversity indices onto the factorial axes of the PCA allows access 
graphically to an overall perception of the correlations between the indices. However, it does not represent the exact reality of these correlations, but only a less distorted description of them. Consequently, in a second stage we completed the procedure by an in-depth analysis of the Spearman rank correlation matrix which gives the pairwise correlations values between all the indices studied. The Spearman's correlations matrix produced less accessible but more precise information on the correlations between the indices studied. More detailed information on both the indices and the approach carried out in the present study can be found in Mérigot et al. (2007a). Taxonomic indices were computed using the PRIMER software (Clarke \& Gorley 2001), while all the other indices and statistical analyses were performed using $\mathrm{R}$ software (version 2.6.2, R Development Core Team 2008). took into account an average of ca. $40 \%$ of the total abundance observed.

Welch's test carried out separately on each diversity descriptor showed no significant seasonal sampling effect (Table 2, p > 0.05). Although based on a limited number of censuses (10 and 12 censuses for the northwest monsoon season and the southeast monsoon season, respectively), these results suggest that pelagic fish diversity did not strongly vary with seasons in the study zone. We also roughly assessed the spatial variation of each index within the study zone. Welch's tests carried out separately on each diversity descriptor showed no significant spatial sampling effect, except for rarity between the northern and southern zones $(p=0.01)$. This latter result was explained by the fact that the only 3 stations containing rare species in the study zone were located in the northern zone. With the exception of rarity, this result suggests that diversity indices do not strongly vary within the entire study zone.

\section{RESULTS}

A total of 58970 individuals, belonging to 27 fish species (25 teleosts and 2 elasmobranchs) and 14 families, were found in the 22 visual censuses analysed (Fig. 2). Rarefaction curves were constructed to determine whether the sampling effort, taken as the number of individuals observed (for individual-based curves, Fig. 3a) or the cumulative number of samples (for sampledbased curves, Fig. 3b), could adequately estimate species richness in the study zone. In both cases, the curves did not fully stabilise towards asymptotic values (Fig. 3). Nevertheless, while there was no sign of having collected all the potential species, our result also suggests that increasing the sampling effort would only result in a slight increase in number of species observed.

Mean values of each species diversity index were mentioned to provide a baseline state in order to monitor future changes in species diversity at this study zone (Table 2). The coefficients of variation for each index of diversity, generally under 0.50 , suggest quite low variability in the estimation of the diversity index values in the entire zone and period studied. The only exception concerned the index of rarity for which the coefficient of variation reached 2.50. The number of species found during each visual FAD census varied between 7 and 18, with a mean value (SD) of 12.27 (2.29). The mean value of $d$ was 0.4032 , showing that the dominant species
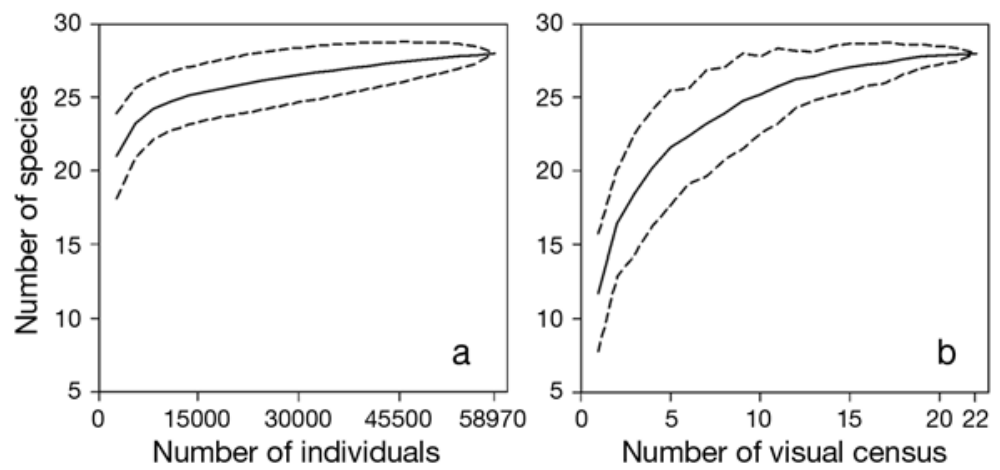

Fig. 3. (a) Individual-based species rarefaction curves and (b) sample-based species rarefaction curves (20 random permutations of the data)

Table 2. Mean value and coefficient of variation of the diversity indices. Welch's test for 'sampling season' and 'sampling zones' (north vs. south and east vs. west) effects. Indice codes as in Table 1. Significant values $(p<0.05)$ are marked by an asterisk

\begin{tabular}{|lrcrrrrrrr|}
\hline & \multirow{2}{*}{ Mean } & CV & \multicolumn{2}{c}{ Season } & \multicolumn{2}{c}{ North-South } & \multicolumn{2}{c|}{ East-West } \\
& & & $t$ & $\mathrm{p}$ & \multicolumn{1}{c}{$t$} & $\mathrm{p}$ & $t$ & $\mathrm{p}$ \\
\hline$S$ & 12.27 & 0.18 & 0.05 & 0.49 & 0.03 & 0.54 & -0.14 & 0.54 \\
$D_{\mathrm{mg}}$ & 1.55 & 0.21 & 0.03 & 0.46 & -0.40 & 0.67 & 0.26 & 0.37 \\
$H^{\prime}$ & 1.32 & 0.35 & 0.60 & 0.28 & 0.18 & 0.43 & 0.68 & 0.23 \\
$1-D$ & 0.62 & 0.36 & 0.56 & 0.30 & 0.04 & 0.44 & 0.59 & 0.29 \\
$E_{\text {Heip }}$ & 0.29 & 0.55 & 0.35 & 0.33 & 0.57 & 0.28 & 0.42 & 0.34 \\
$1 / d$ & 2.48 & 0.35 & 0.24 & 0.43 & 0.15 & 0.43 & 0.21 & 0.42 \\
$\Delta$ & 40.54 & 0.38 & -0.23 & 0.62 & 0.49 & 0.31 & 0.52 & 0.30 \\
$\Delta^{*}$ & 64.10 & 0.14 & -1.91 & 0.96 & 1.17 & 0.12 & -0.06 & 0.54 \\
$\Delta^{+}$ & 67.13 & 0.05 & 0.48 & 0.30 & -2.45 & 0.98 & 1.72 & 0.07 \\
$\Lambda^{+}$ & 311.40 & 0.21 & 0.64 & 0.26 & -0.23 & 0.59 & 0.29 & 0.41 \\
Rarity & 0.14 & 2.50 & -0.44 & 0.43 & 1.88 & $0.01^{*}$ & 0.74 & 0.07 \\
\hline
\end{tabular}



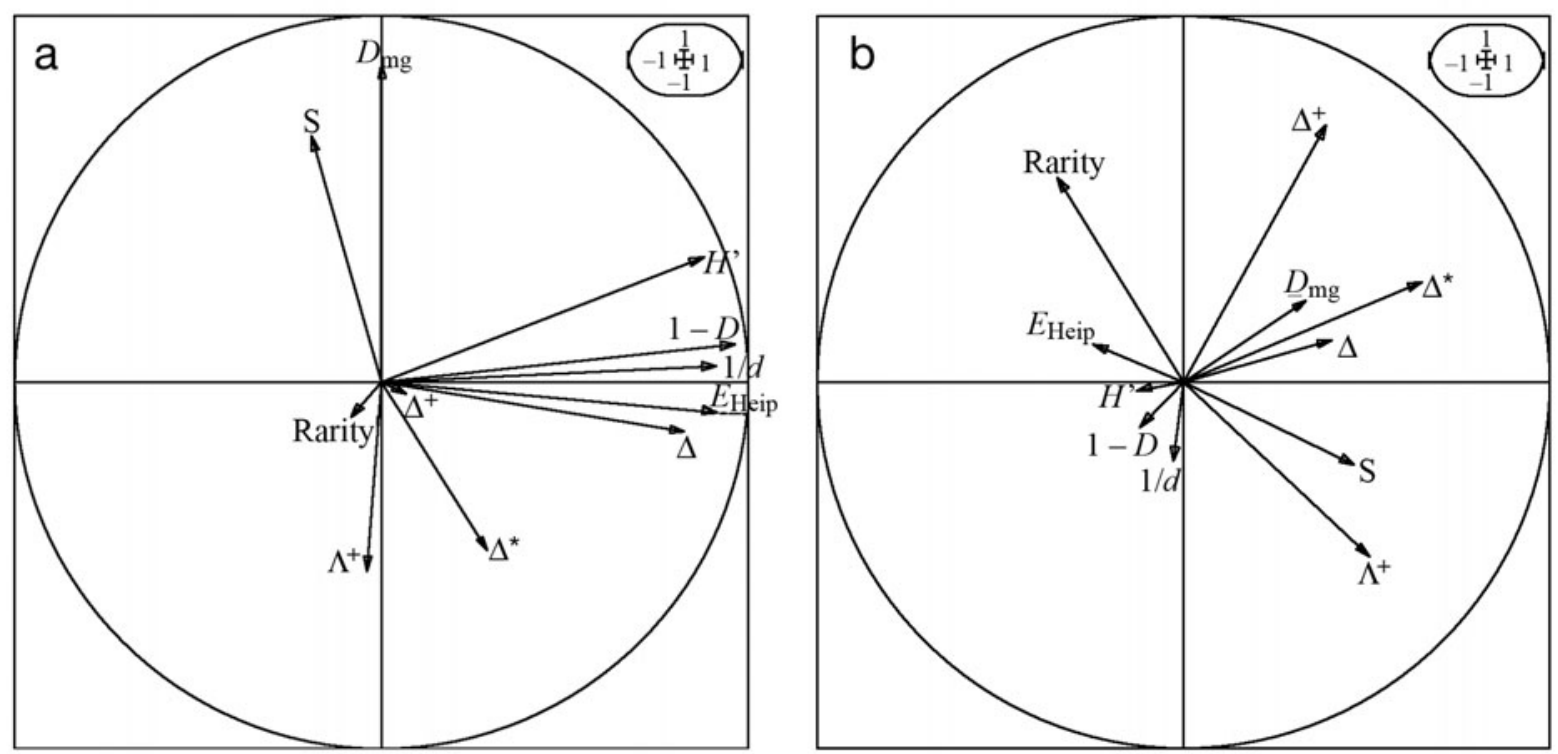

Fig. 4. Projection of the diversity indices onto (a) the first factorial plan (axis 1 horizontal, axis 2 vertical) and (b) the second factorial plan (axis 3 horizontal, axis 4 vertical). Indices codes as in Table 1

The projection of indices onto the correlation circle of the PCA allowed us to graphically display different groups of diversity indices (Fig. 4). The first 4 principal components accounted for $81.8 \%$ of the total inertia. The first principal component $(38.3 \%)$ was highly correlated with all evenness indices $\left(E_{\text {Heip }}\right.$ and $\left.1 / d\right)$, the 2 heterogeneous indices $\left(H^{\prime}\right.$ and $\left.1-D\right)$ and with one of the taxonomic diversity indices $(\Delta)$. The second principal component $(17 \%)$ was mainly explained by the 2 indices focused on the number of species ( $S$ and $D_{\mathrm{mg}}$ ). These 2 descriptors were not significantly correlated with the other indices (see Table 3). These results indicate that information provided by the number of species ( $S$ and $D_{\mathrm{mg}}$ ) on species diversity patterns of pelagic fishes is clearly different from that given by the other diversity descriptors. The projection of the 3 other taxonomic indices $\left(\Delta^{*}, \Delta^{+}\right.$and $\left.\Lambda^{+}\right)$and rarity showed that none of these indices contributed to the first 2 principal components. In contrast, they played a stronger role in the formation of axis $3(14.6 \%)$ and axis $4(11.9 \%$, Fig. $4 b)$.

The Spearman's correlations matrix provides more precise information on the correlation among the indices studied. The weak Spearman's correlations observed between rarity, $\Delta^{*}, \Delta^{+}$and $\Lambda^{+}$(see Table 3 ) confirmed the PCA results that each of them provided complementary information on pelagic fish species diversity in the study zone. Spearman's correlations also confirmed that $\Delta$ was highly correlated with both the evenness and the heterogeneous indices. In addition, $\Delta$ appeared to be significantly correlated with $\Delta^{*}$. This latter correlation was not obvious on the first 4 axes of the PCA. It illustrates that the single use of PCA results failed to precisely represent all the corre-

Table 3. Spearman's rank correlation matrix between the 11 selected diversity indices. All significant correlations are marked by an asterisk $(\mathrm{p}<0.05)$. Indices codes as in Table 1 . Boxes show indices that are significantly correlated

\begin{tabular}{|c|c|c|c|c|c|c|c|c|c|c|c|}
\hline $\begin{array}{l}S \\
D_{\mathrm{mg}}\end{array}$ & $\begin{array}{c}S \\
0.63^{*}\end{array}$ & $D_{\mathrm{mg}}$ & & & & & & & & & \\
\hline$H^{\prime}$ & 0.06 & 0.24 & $H^{\prime}$ & & & & & & & & \\
\hline $1-D$ & -0.12 & 0.01 & $0.92^{*}$ & $1-D$ & & & & & & & \\
\hline$E_{\text {Heip }}$ & -0.39 & -0.13 & $0.85^{*}$ & $0.89^{*}$ & $E_{\text {Heip }}$ & & & & & & \\
\hline $1 / d$ & -0.12 & -0.02 & $0.76^{*}$ & $0.92^{*}$ & $0.74^{*}$ & $1 / d$ & & & & & \\
\hline$\Delta$ & -0.07 & 0.06 & $0.57^{*}$ & $0.69^{*}$ & $0.63^{*}$ & $0.75^{*}$ & $\Delta$ & & & & \\
\hline$\Delta^{*}$ & -0.06 & -0.12 & 0.03 & 0.10 & 0.17 & 0.15 & $0.65^{*}$ & $\Delta^{*}$ & & & \\
\hline$\Delta^{+}$ & -0.08 & 0.21 & -0.03 & -0.02 & 0.08 & -0.08 & 0.19 & 0.27 & $\Delta^{+}$ & & \\
\hline$\Lambda^{+}$ & 0.12 & -0.36 & -0.17 & -0.05 & -0.12 & 0 & 0.10 & 0.35 & -0.05 & $\Lambda^{+}$ & \\
\hline Rarity & -0.15 & -0.07 & 0.03 & -0.09 & 0.03 & -0.20 & -0.11 & 0.05 & 0 & -0.19 & Rarity \\
\hline
\end{tabular}


lations between indices and then to draw a reproducible typology of the indices. In contrast, the simultaneous analysis of PCA and Spearman's correlation coefficients provided a basis for grouping the 11 species diversity descriptors studied into 6 complementary components of diversity: (1) number of species $(S$ and $\left.D_{\mathrm{mg}}\right),(2)$ evenness $\left(E_{\text {Heip }}, 1 / d, H^{\prime}, 1-D\right),(3)$ rarity and 3 components based on taxonomy: (4) $\Delta^{*}$ (5) $\Delta^{+}$ and (6) $\Lambda^{+}$. Note that $\Delta$ might belong to 2 different groups as it showed strong and significant correlation with both the evenness group and with $\Delta^{*}$. All the other indices studied belonged to a single group of descriptors.

\section{DISCUSSION}

The present study is the first to assess pelagic fish diversity from data on fish aggregations around drifting FADs. Independently of the sampling techniques used, it is also the first one to propose the simultaneous analysis of several components of pelagic fish diversity to better capture the complexity of the diversity of open-ocean communities. The few publications providing assessment of pelagic fish diversity are restricted to describing species richness (Massuti et al. 1999, Smith \& Brown 2002, Worm et al. 2003). Only Deudero et al. (1999) analysed 2 components of pelagic fish diversity in a coastal area of the Mediterranean Sea, but they restricted their analysis to species richness and evenness. To our knowledge, taxonomic indices have never been calculated for pelagic fish assemblages to date.

\section{A comment on sampling effort}

It is worth noting that fishery-independent data are always much less abundant than fishery-dependent data due to the difficulty and cost of accessing openocean areas in research vessels. This is the reason why the present study is restricted to 22 visual censuses. While such an effort is unique in the world, for a sampling design based on a set of standardized visual censuses in the open ocean, we acknowledge that it may be insufficient to address biological and ecological conclusions about the observed distribution of species diversity, and this would clearly be beyond the scope of the present study. In contrast, despite a limited sampling effort some of our results suggest that our approach may provide a representative picture of species diversity for the zone and period studied.

Firstly, while rarefaction curves did not reach an asymptotic maximum, we have to keep in mind that such a limitation is a general result (Margules \& Pressey 2000), which also traditionally occurs in other environments and with larger databases (see an illustration in a study of Mediterranean groundfishes based on 600 trawl hauls, Gaertner et al. 2007). In the present study it is more important to note that the rarefaction curves also suggested that increasing the sampling effort would have probably revealed only few additional species, showing that the area studied has been thoroughly sampled by the set of 22 visual censuses. Consequently we can expect that increasing the sampling effort would not have strongly modified our assessment of species richness indices. Secondly, we found both a general low variability for each index (except for rarity, see CV in Table 2) and non-significant seasonal and spatial variability for the 11 diversity indices considered. The only exception still concerned rarity (for the north-south effect). Except for this index, our results suggested that the size of our sampling effort was large enough to provide a reproducible characterization of each independent pelagic fish diversity component considered for the period and zone studied.

\section{The multi-component structure of pelagic fish diversity}

The whole set of diversity indices considered in the present study may be split into a few distinct and complementary groups of descriptors of pelagic fish diversity. This result shows that a single index, such as the species richness or Shannon-Wiener, cannot provide a complete description of the pelagic fish species diversity in the study zone. It demonstrates the multi-component aspects of species diversity suggested by theoretical studies (Purvis \& Hector 2000), but explicitly shown only in a limited number of experimental studies (Wilsey et al. 2005, Mérigot et al. 2007a,b) and never, to date, for pelagic fish assemblages. While our study dealt with 4 theoretical components of biodiversity, we displayed 6 complementary groups of descriptors. These results emphasize that some components of pelagic diversity are multi-components themselves and therefore require the simultaneous use of several complementary indices in order to be accurately described and monitored.

On the other hand, when a component can be described by several redundant indices, we propose selecting the index that is most intuitively simple to understand and easy to calculate. For instance, BergerParker index $1 / d$, which is simple to understand and easy to measure (the identities of species other than the most abundant species do not need to be deter- 
mined), might be a good candidate for summarizing the evenness component of diversity in a single value. With regard to species richness $S$ and Margalef $D_{\mathrm{mg}}$ the same kind of strategy could be done for selecting $S$ rather than $D_{\mathrm{mg}}$. This reasoning is clearly a step towards the approach stressed by Purvis \& Hector (2000) stating that 'the stronger the correlations between diversity indices, the more reasonable it will be to reduce multiple measures to a few principal components, to create dimensions of diversity'. This led us to propose a preliminary short list of diversity indices based firstly on their complementarity and secondly on their simplicity. In the present study, species diversity around FADs could be simultaneously described by: (1) $S,(2) 1 / d,(3) \Delta^{*},(4) \Delta^{+},(5) \Lambda^{+}$and (6) rarity. Nevertheless, we have to keep in mind that rarity showed a high variability, suggesting that our sampling effort may not be suitable for properly assessing this index. More generally, whatever the ecosystem and the sampling effort, definitions of rarity, including ours, are based on subjective choices (Gaston 1994, Magurran 2004, Mérigot et al. 2007a), and this concept should be used carefully.

From a conservation perspective, our results suggest that the complementary diversity indices may not respond in the same way to natural and anthropogenic factors, making the forecast of impact difficult without consideration of all these descriptors. Along with other information (distributional patterns of fishing fleets and of the main targeted species, size-structure, etc.), the monitoring of this set of complementary diversity indices could help fishery managers make management decisions, such as the design and location of marine protected areas. However, although the nature and the number of diversity components we found in open-ocean FADs are very similar to those described for groundfishes in the North Mediterranean Sea (Mérigot et al. 2007a,b), we cannot consider this short list as a universal one for describing fish diversity. The present analytical approach should be applied to other areas and communities in order to define to what extent the relationships we observed could be generalized. In addition, the set of initial diversity indices computed in a study (here the set of 11 indices) cannot be easily defined a priori. The selection of the initial components and descriptors to be used to describe species diversity should depend on both the objectives of the study and the nature of the available data (presence-absence or abundance data, knowledge of some biological traits for the whole assemblage under study, etc.). Our approach has the advantage of being flexible and allows the possibility of defining (and modifying) the list of indices and components initially computed.

\section{Assessing the fish pelagic diversity from data collected under FADs, pros and cons}

Diversity studies are often strongly affected by the sampling techniques (Magurran 2004) and no sampling technique can be considered perfect. The use of visual census around FADs as an approach for analysing fish community diversity in the pelagic environment depends on 2 assumptions. The first is that FAD constitutes a relevant tool to efficiently estimate the species diversity of pelagic fishes. Castro et al. (2001) found records of 333 species (96 families) observed at least once around drifting or anchored FADs. However, in accordance with several studies conducted at a regional scale on the basis of a single sampling technique, our results showed that there is evidence for 'regular' presence of less than 30 families around FADs, confirming what has been found by other authors (Kingsford 1993, Deudero et al. 1999, Massuti et al. 1999, Romanov 2002). This clearly suggests that the behaviour of fishes regarding FADs may vary according to the species and that only some species seem to have strong attraction tendencies to FADs, forming aggregations. But the fact that fishes have different behaviours regarding FADs simply indicates that FADs cannot be used to assess the full species richness of fish pelagic assemblages, but should be limited to monitor the diversity of a subset of pelagic species. It is important to note that samplings made by fishing vessels respond to similar constraints: the selectivity of each fishing gear depends on the behaviour of each species, some being very vulnerable to the fishing gear, while others are not.

The second assumption is that visual censuses by divers efficiently estimate the species diversity of fish around FADs. Underwater visual census techniques have been extensively used to assess fish assemblage structure in coastal benthic ecosystems, in both temperate and tropical areas (e.g. Samoilys \& Carlos 2000). In contrast, this technique has not been used to estimate the structuring of pelagic assemblages in oceanic waters. The use of visual censuses in the pelagic domain not only shares some drawbacks with benthic surveys, but it also presents additional challenges. Given that diving is constrained by depth and duration, visual censuses are limited to the shallowest part of the water column (epipelagic domain). In addition, visual censuses are strictly limited to counting diurnally active species, missing nocturnal aggregations if they occur. Furthermore, even if water clarity is usually better in oceanic waters than in coastal ecosystems, visibility limitations led us to restrict the sampling census to a short semi-spherical volume of water centered around the FAD (here with a horizontal radius of $50 \mathrm{~m}$ and a vertical radius of $30 \mathrm{~m}$ ). Whatever the conditions 
we could expect in other oceanic waters, our technique will never allow a reproducible estimation of circumnatant fishes (i.e. species associated with a FAD that are usually found aggregated far away from the FADs), such as tuna. Also, species living in very large schools (thousands of individuals), a common situation in the pelagic domain, might be underestimated in visual censuses, as divers may have difficulty both observing the entire school and estimating the number of individuals in a school (see electronic appendix at www.intres.com/articles/suppl/m366p175_app.pdf). In the present study, we employed abundance classes when the number of individuals counted for a single species was more than 50. Although we cannot obtain a precise count for the most abundant species, the simultaneous use of both direct observations by divers and video recording allowed us to estimate the order of magnitude of the potential inaccuracy of this assessment. Underwater acoustic techniques (echo-sounders) would be more appropriate than visual censuses to assess the size of large fish schools, such as those of tuna (Josse et al. 1999). While acoustic survey techniques are valid for only a small number of species and are not sufficient on their own to measure the diversity of pelagic fishes, they could complement visual censuses carried out at FADs.

Otherwise, visual censuses carried out in the pelagic open water are free from several constraints traditionally encountered in benthic reef environments. One of the major problems with visual censuses carried out in coastal reef ecosystems is the difficulty of assessing the numerous species that live within the reef structure (Harmelin-Vivien et al. 1985, Tessier et al. 2005). These fishes occupy spaces within the coral reef structure and are very difficult to observe, and therefore indices based on abundance and on presence-absence data may be largely underestimated. In reef ecosystems, mimetic processes, which are very common, can provide another difficulty for accurately assessing diversity (Harmelin-Vivien et al. 1985). While some pelagic species also might develop mimetic colouring during juvenile stages (see Castro et al. 2001), this phenomenon is limited and should not significantly affect visual censuses in the pelagic waters. The density of species inhabiting pelagic environments is lower than in benthic ecosystems, particularly in coral reefs. As a consequence, diversity descriptors based on presence-absence data (species density, $\Delta^{+}$, etc.) are probably less biased by visual censuses performed in the pelagic domain than in the benthic domain.

Our analysis showed that visual censuses of fish communities at FADs cannot provide a complete and exhaustive measure of pelagic fish diversity in the open ocean. In the present study, we omitted both circumnanant fishes and species commonly found in waters deeper than $50 \mathrm{~m}$, and by so doing we eliminated some species playing important roles both for fisheries (e.g. some tuna) and for the functioning of the ecosystem (e.g. some top predators). However, this does not invalidate the potential use of visual of censuses at FADs to monitor the fish diversity in pelagic ecosystems, since 'relative' indices of biodiversity can be used. Indeed, because of the complexity of properly assessing biodiversity, regardless of the ecosystem, Margules \& Pressey (2000) highlighted the need to use surrogates such as subsets of species as measures of biodiversity. These authors stated 'that surrogates or partial measures of biodiversity must be used to estimate similarity or difference among areas within a planning region'. To do so, it is necessary to carefully characterize the species assemblage accessible to visual census techniques. In this respect, our approach allowed us to focus the present study on a very welldelimited assemblage of species: the part of the pelagic fish community (1) living in the epipelagic domain, (2) naturally attracted to FADs and (3) aggregated in the vicinity of FADs during daytime (i.e. intraand extranatant species according to Fréon \& Dagorn 2000). Some of these species are common by-catch in pelagic fisheries (including industrial purse seiners). Thus, performing standardized visual census surveys under FADs might constitute a fruitful approach for monitoring the effects of overfishing, climate change and other forms of human impacts on this surrogate of the pelagic biodiversity in tropical oceans.

Techniques other than visual censuses, notably data collected on commercial fishing vessels by scientific observers, could also be used to sample fish diversity around FADs and complement data from visual surveys. The main advantage of fishery observers' data on drifting FADs is that they could be easier to collect and therefore could provide larger databases than fisheryindependent sampling techniques. Purse seine data would be very valuable in this respect. One advantage is that purse seiners sample a wider variety of circumnatant fishes. However, purse seining misses most of the small individuals that escape through the mesh (see Romanov 2002). Similarly, Worm et al. (2003) used scientific observer records from pelagic longline fisheries in the Atlantic and Pacific Oceans. They recognized that if pelagic longlines catch a wide range of species over vast areas, they only sample the largest individuals vulnerable to baited hooks. Thus, it is not surprising to note that the vast majority of species observed in the present study are not caught by longliners and were not included in the Worm et al. (2003) analysis. More generally, the use of commercial fishing gear (e.g. purse seine, trawl, longline, etc.) for sampling pelagic fish communities falls quite short of meeting the requirements for describing species diver- 
sity (similar availability and catchability of pelagic species, random sampling, etc.). The use of fisheriesdependent techniques are notably limited to commercially fished areas, as no fishery observer data exists for areas outside commercial fishing grounds. Finally, the sampling is driven by the behaviour of fishermen, which makes sampling standardization difficult and thus limits the use of such data for monitoring diversity in both space and time. In the present study, FADs were deployed by fishermen, but one can envision the deployment of scientific FADs totally independent of fishermen activities.

In short, each sampling technique (including visual surveys around FADs) might only provide relative values of pelagic biodiversity, and it would be wishful thinking to imagine that a single sampling technique might achieve an exhaustive assessment of fish diversity in open-ocean environments. We think it is more reasonable to view each sampling technique as limited to characterizing part of the diversity of the pelagic ecosystem. In this context, our visual census approach could complement traditional techniques that are based on commercial catches. We are conscious that conducting visual censuses around FADs that may be far away from any land can involve knowledge, logistic and financial constraints. The development of appropriate automated instrumented buoys that could catch the main components of fish aggregations would greatly improve the collection of data. Anyway, we have shown that even restricted sampling sizes (22 samples) can provide reliable data as a basis for characterizing most of the diversity components in an area. We consider that it is urgent to develop large-scale projects that collect and combine fishery-dependent and fishery-independent data in order to improve our ability to efficiently monitor the diversity of openocean waters in the future. The monitoring of FADs can provide a precious help in achieving this ambitious goal.

Acknowledgements. This study was done as part of the FADIO (Fish Aggregating Devices as Instrumented Observatories of pelagic ecosystems) project, funded by the DG Research (QLRI-CT-2002-02773). We acknowledge multiple other members of the FADIO project in the collection of the data from the Indian Ocean Explorer. We are grateful to D. Bidwell, who provided comments on early drafts and to J. P. Durbec for his advice in the choice of statistical analyses.

\section{LITERATURE CITED}

Beisel JN, Usseglio-Polatera P, Bachmann V, Moreteau JC (2003) A comparative analysis of evenness index sensitivity. Int Rev Hydrobiol 88:3-15

Berger WH, Parker FL (1970) Diversity of planktonic Foraminifera in deep sea sediments. Science 168:1345-1347
Boyle TP, Smillie GM, Anderson JC, Beeson DR (1990) A sensitivity analysis of 9 diversity and 7 similarity indexes. Res J Water Pollut Control Fed 62:749-762

Castro JJ, Santiago JA, Santana-Ortega AT (2001) A general theory on fish aggregation to floating objects: an alternative to the meeting point hypothesis. Rev Fish Biol Fish $11: 255-277$

Clarke KR, Gorley RN (2001) PRIMER V5: User manual. PRIMER-E Ltd, Plymouth

Clarke KR, Warwick RM (1998) A taxonomic distinctness index and its statistical properties. J Appl Ecol 35:523-531

Clarke KR, Warwick RM (1999) The taxonomic distinctness measure of biodiversity: weighting of step lengths between hierarchical levels. Mar Ecol Prog Ser 184:21-29

Clarke KR, Warwick RM (2001) A further biodiversity index applicable to species lists: variation in taxonomic distinctness. Mar Ecol Prog Ser 216:265-278

Dempster T, Taquet M (2004) Analysis of the literature on fish aggregation devices (FAD) research; gaps in current knowledge and future research directions for studies of FAD-associated fish. Rev Fish Biol Fish 14:21-40

Deudero S, Merella P, Morales-Nin B, Massuti E, Alemany F (1999) Fish communities associated with FADs. Sci Mar 63:199-207

Ellingsen KE (2001) Biodiversity of a continental shelf softsediment macrobenthos community. Mar Ecol Prog Ser 218:1-15

Fonteneau A, Pallares P, Pianet R (2000) A worldwide review of purse seine fisheries on FADs. In: Le Gall JY, Cayre P, Taquet $\mathrm{M}$ (eds) Peche thoniere et dispositifs de concentration de poissons. Ed Ifremer, Actes Colloq 28:15-34

$>$ Fréon P, Dagorn L (2000) Review of fish associative behaviour: toward a generalisation of the meeting point hypothesis. Rev Fish Biol Fish 10:183-207

Gaertner JC, Bertrand JA, Gil de Sola L, Durbec JP, Ferrandis E, Souplet A (2005) Large spatial scale variation of demersal fish assemblages structure on the continental shelf of the NW Mediterranean Sea. Mar Ecol Prog Ser 297:245-257

> Gaertner JC, Bertrand JA, Relini G, Papaconstantinou C and others (2007) Spatial pattern in species richness of fish demersal assemblages on the continental shelf of the northern Mediterranean Sea: a multiscale analysis. Mar Ecol Prog Ser 341:191-203

Gaston KJ (1994) Rarity. Chapman and Hall, London

Gaston KJ, Spicer VI (1998) Biodiversity: an introduction. Blackwell Science, Oxford

- Gray S (2002) Species richness of marine soft sediments. Mar Ecol Prog Ser 244:285-297

Harmelin-Vivien M, Harmelin JG, Chauvet C, Duval C and others (1985) Evaluation visuelle des peuplements et populations de poissons: méthodes et problèmes. Rev Ecol (Terre Vie) 40:467-539

Heip C (1974) A new index measuring evenness. J Mar Biol Assoc UK 54:555-557

Jolliffe IT (1986) Principal component analysis. SpringerVerlag, New York

Josse E, Bertrand A, Dagorn L (1999) An acoustic approach to study tuna aggregated around fish aggregating devices in French Polynesia: methods and validation. Aquat Living Resour 12:303-313

Kingsford MJ (1993) Biotic and abiotic structure in the pelagic environment: importance to small fish. Bull Mar Sci 53: 393-415

Magurran AE 2004. Measuring biological diversity. Blackwell Publishing, Oxford

Margalef R (1958) Information theory in ecology. Gen Syst 3: $36-71$ 
Margules CR, Pressey RL (2000) Systematic conservation planning. Nature 405:243-253

Massuti E, Morales-Nin B, Deudero S (1999) Fish fauna associated with floating objects sampled by experimental and commercial purse nets. Sci Mar 63:219-227

Mérigot B, Bertrand JA, Mazouni N, Manté C, Durbec JP, Gaertner JC (2007a) A multi-component analysis of species diversity of ground fish assemblages on the continental shelf of the Gulf of Lions (north-western Mediterranean Sea). Estuar Coast Shelf Sci 73:123-136

Mérigot B, Bertrand JA, Gaertner JC, Durbec JP, Mazouni N, Manté C (2007b) The multi-component structuration of the species diversity of groundfish assemblages of the east coast of Corsica (Mediterranean Sea): variation according to the bathymetric strata. Fish Res 88:120-132

- Moreno G, Dagorn L, Sancho G, Itano D (2007) Fish behaviour from fishers' knowledge: the case study of tropical tuna around drifting fish aggregating devices (DFADs). Can J Fish Aquat Sci 64:1517-1528

Parin NV, Fedoryako BI (1999) Pelagic fish communities around floating objects in the open ocean. In: Scott MD, Bayliff WH, Lennert-Cody CE, Schaefer KM (eds) Proc Int Workshop Ecology and Fish for Tunas Associated with Floating Objects. Inter-American Tropical Tuna Commission Special Report 11, La Jolla, CA, p 447-458

Purvis A, Hector A (2000) Getting the measure of biodiversity. Nature 405:212-219

R Development Core Team (2008) R: a language and environment for statistical computing. R Foundation for Statistical Computing, Vienna. Available at: www.R-project.org

Rogers SI, Clarke KR, Reynolds JD (1999) The taxonomic distinctness of coastal bottom-dwelling fish communities of the North-east Atlantic. J Anim Ecol 68:769-782

Romanov EV (2002) By-catch in the tuna purse-seine fisheries of the Western Indian Ocean. Fish Bull (Wash DC) 100: 90-105

Editorial responsibility: Hans Heinrich Janssen, Oldendorf/Luhe, Germany
Rosenzweig ML (1995) Species diversity in space and time. Cambridge University Press, Cambridge

Samoilys MA, Carlos G (2000) Determining methods of underwater visual census for estimating the abundance of coral reef fishes. Environ Biol Fishes 57:289-304

Shannon CE, Weaver W (1949) The mathematical theory of communication. University of Illinois, Urbana, IL

Simpson EH (1949) Measurement of diversity. Nature 163:688

Smith KF, Brown JH (2002) Patterns of diversity, depth range and body size among pelagic fishes along a gradient of depth. Glob Ecol Biogeogr 11:313-322

Smith B, Wilson JB (1996) A consumer's guide to evenness indices. Oikos 76:70-82

Taquet M, Sancho S, Dagorn L, Gaertner JC and others (2007) Characterizing fish communities associated with drifting fish aggregating devices (FADs) in the Western Indian Ocean using underwater visual surveys. Aquat Living Resour 20:331-341

Tessier E, Chabanet P, Pothin K, Soria M, Lasserre G (2005) Visual censuses of tropical fish aggregations on artificial reefs: slate versus video recording techniques. J Exp Mar Biol Ecol 315:17-30

Thomas CD, Mallorie HC (1985) Rarity, species richness and conservation: butterflies of the Atlas Mountains in Morocco. Biol Conserv 33:95-117

> Warwick RM, Clarke KR (1995) New biodiversity measures reveal a decrease in taxonomic distinctness with increasing stress. Mar Ecol Prog Ser 129:301-305

> Wilsey BJ, Chalcraft DR, Bowles CM, Willig MR (2005) Relationships among indices suggest that richness is an incomplete surrogate for grassland biodiversity. Ecology 86 : $1178-1184$

Worm B, Lotze HK, Myers RA (2003) Predator diversity hotspots in the blue ocean. Proc Natl Acad Sci USA (100) $17: 9884-9888$

Submitted: December 10, 2007; Accepted: April 28, 2008 Proofs received from author(s): August 23, 2008 